\title{
Discoid Lupus Erythematosus leading to Squamous Cell Carcinoma
}

\author{
Wg Cdr S Grover*, Gp Capt PS Murthy ${ }^{+}$,Wg Cdr R Rajagopal\#, Gp Capt YP Jalpota (Retd) ${ }^{* *}$, \\ KV Sudha ${ }^{++}$
}

MJAFI 2007; 63 : 184-185

Key Words : Discoid lupus erythematosus; Squamous cell carcinoma

\section{Introduction}

$\mathrm{D}$ iscoid lupus erythematosus (DLE) is a benign disorder of the skin, clinically characterized by red scaly patches which heal with atrophy, scarring and pigmentary changes and histopathologically by vacuolar degeneration of basal cell layer of epidermis and patchy dermal lymphocytic infiltrate. DLE is subdivided into a localized form in which lesions are confined to the face and neck or a disseminated form in which lesions also occur elsewhere on the body [1]. Malignant transformation is a rare complication of this condition. We report a case of squamous cell carcinoma (SCC) developing over lesions of disseminated DLE.

\section{Case Report}

A 46 year old male farmer developed multiple erythematous patches over the scalp, face, chest, upper back and outer aspects of both arms. These patches progressed gradually over four months, leaving residual depigmented areas in the centre with loss of overlying hair. The patches over the scalp coalesced to involve almost the entire scalp. About a year later, an ulcer formed on the vertex of the scalp which progressed gradually, to form a fungating growth with foul smelling discharge. There was no history of trauma, photosensitivity, prior drug intake, exposure to ionising radiation or arsenicals, fever, weight loss, joint pains, fatigue, urinary disturbances, diabetes mellitus, oral ulcers, thrombophlebitis, chillblains, Raynaud's phenomenon or bleeding tendencies.

General examination was unremarkable except for firm, nontender, discrete, mobile lymph nodes of the right occipital group $1.5 \mathrm{~cm}$ in size. Systemic examination was normal. Dermatological examination revealed multiple, well defined, atrophic, alopecic, depigmented plaques with irregular hyperpigmented margins, varying in size from $0.5-18 \mathrm{~cm}$, distributed over the fronto-parieto-occipital region of scalp, temporozygomatico-mandibular region of face, helix and concha of ears, upper arms, front of the chest and upper back. Scaling with 'tin tack' sign was noticed at active erythematous margins at a few places on the scalp. A single, firm, cauliflower-like growth, $11 \times 17 \mathrm{~cm}$ in size, with everted overhanging edges and foul smelling discharge was present over the verticooccipital region of the scalp in the midst of the depigmented patch (Fig.1). The mass was friable, bled on touch and appeared fixed to the underlying bone. The surface of the tumor had scattered bleeding points, erosions and brown crusts. Oral and nasal mucosa, eyes, nails, palms, soles, external genitalia, perianal region and joints were normal.

Routine haematological and biochemical investigations were normal. Chest radiograph and ultrasound of abdomen was normal. Fine needle aspiration cytology of right occipital lymph node revealed reactive mononuclear cell infiltrate. Though serum antinuclear antibody (ANA) was positive, he did not satisfy the criteria for systemic lupus erythematosus (SLE). Histology of the depigmented patch on the scalp revealed atrophic thinned epidermis with hyperkeratosis, vacuolar degeneration of basal cells, loss of rete ridges, dermal edema with exudation of neutrophils, loss of hair follicles and adnexa with patchy dermal lympocytic infiltrate, confirming the diagnosis of DLE (Fig. 2). Histology of the tumor revealed infiltrative epidermal masses in the dermis, moderate lymphoid infiltrates between cell aggregates, keratin pearls with areas of dysplasia and increased mitotic activity, confirming the diagnosis of SCC (Fig.3). Oral hydroxychloroquine and topical steroids were exhibited for management of DLE while SCC was managed by the surgeons with wide excision of the tumor followed by skin grafting.

\section{Discussion}

Genetic factors and somatic mutations are implicated in the pathogenesis of DLE. Three to five somatic mutations affecting autosomal genes and one mutation involving X-linked gene in lymphocytic stem cells of predisposed individuals, results in development of a forbidden clone of lymphocytes which synthesize cellular

\footnotetext{
${ }^{*, \# C l a s s i f i e d ~ S p e c i a l i s t ~(D e r m a t o l o g y, ~ V e n, ~ L e p), ~}{ }^{++}$Senior Resident (Dermatology, Ven, Lep), ${ }^{* *}$ Ex- Senior Advisor (Pathology), Command
} Hospital Air Force, Bangalore 560007. ${ }^{+}$Classified Specialist (Dermatology, Ven, Lep), 7 Air Force Hospital, Kanpur. 


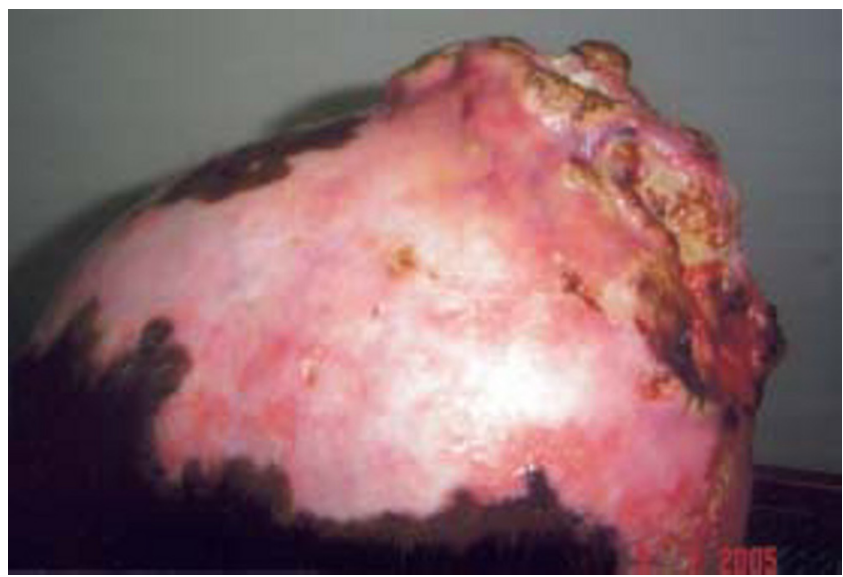

Fig. 1: Tumorous growth of SCC over lesion of DLE: Right lateral view of scalp

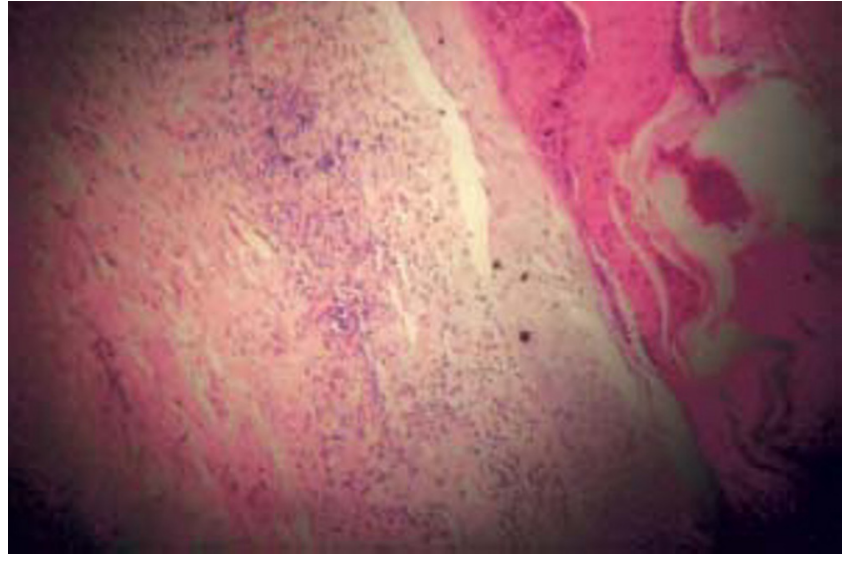

Fig. 2: Photomicrograph of depigmented patch from the scalp showing features of DLE (H\&E; 100X)

autoantibodies [1]. Four temporally sequential phases are a prerequisite for clinical expression of lupus viz. inheritance of susceptibility genes, induction of autoimmunity by autoreactive $\mathrm{T}$ cells, expansion of autoimmune process with autoantibodies and immunological injury. Immunological injury is attributed to the action of autoantibodies and the immune complexes they form, which causes tissue damage [2].

There have been sporadic reports of neoplastic change in DLE which range from SCC and basal cell carcinoma to malignant fibrous histiocytoma and atypical fibroxanthoma [3]. The incidence of SCC developing in DLE ranges from $3.3-3.4 \%$ in various studies [4,5].

The interval between development of DLE and SCC has varied from 4 - 20 years $[5,6]$, but our case developed SCC within a year of appearance of DLE lesions. This could be explained by the high risk factors in this case. Precipitating factors for SCC are age more than 40 years, male sex, sun/ultraviolet ray exposure, skin pigmentation and chronic inflammatory processes. There is an inverse relation between skin pigmentation and development of SCC because of the protective effect of melanin [2].

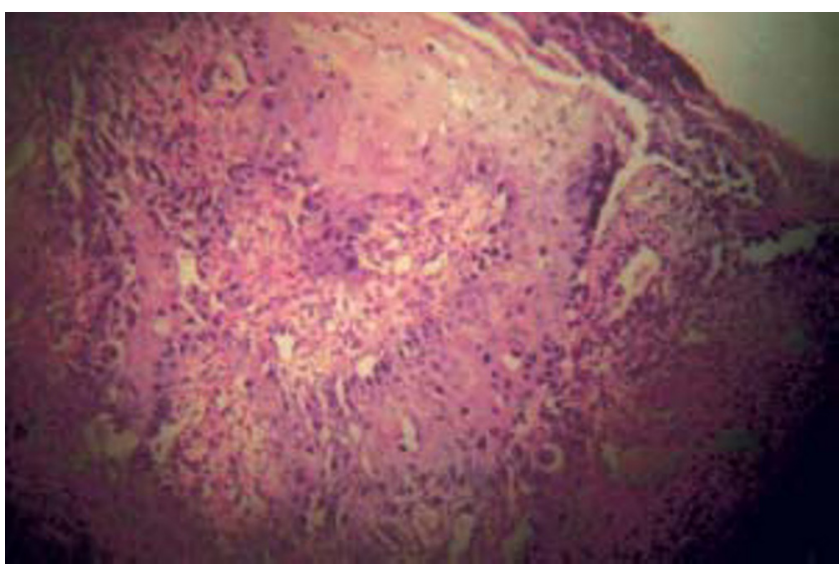

Fig. 3: Photomicrograph of tumor from the scalp showing features of SCC (H\&E; 100X)

The long term prognosis of such cases is varied. SCC arising in DLE is regarded as a locally aggressive but low grade carcinoma with recurrences and invasion into the underlying skull and dura. One study reported local recurrences in about $20 \%$ and metastasis in $30 \%$ cases [7]. Death has also been reported from multiple metastases [8].

A rare case of SCC developing over disseminated DLE lesions within a short span has been reported. The case is under regular follow-up to detect local recurrences, distant metastases and progression to SLE.

\section{Conflicts of Interest}

None identified

\section{References}

1. Goodfield MJD, Jones SK, Veale DJ. The connective tissue diseases (Discoid Lupus Erythematosus). In: Burns T, Breathnach S, Cox N, Griffiths C. Rook's Textbook of Dermatology. $7^{\text {th }}$ ed. Oxford: Blackwell Science, 2004: 5-24.

2. Grossman D, Leffell DJ. Squamous Cell Carcinoma. In: Freeberg IM, Eisen AZ, Wolff K, Auster KF, Goldsmith LA, Katz SI. Fitzpatrick's Dermatology in Internal Medicine. $6^{\text {th }}$ ed. New York: McGraw Hill, 2003; 737-47.

3. Matsushita S, Ishihara T, Kageshita T, Egawa K, Miyake T, Ono T. Multiple squamous cell carcinomas arising in lesions of discoid lupus erythematosus. J Dermatol 2004; 31:73-5.

4. Millard LG, Barker DJ. Development of squamous cell carcinoma in chronic DLE. Clin Exp Dermatol 1978; 3: 161.

5. Pandhi RK, Gupta R, Kumar SA, Bhutani LK. Discoid Lupus Erythematosus in Northern India. Ind J Dermatol Venereol Leprol 1984; 50: 97-9.

6. Nair VL, Chacko M. Disseminated discoid lupus erythematosus with squamous cell carcinoma. Indian J Dermatol Venereol Leprol 1991; 57: 196-7.

7. Sulica VI, Kao GF. Squamous-cell carcinoma of the scalp arising in lesions of discoid lupus erythematosus. Am J Dermatopathol 1988; 10:137-41.

8. Martin S, Rosen T, Locker E. Metastatic squamous cell carcinoma of the lip. Occurrence in blacks with discoid lupus erythematosus. Arch Dermatol 1979; 115:1214. 